\title{
Estimation of the residual resource of wooden structures by changing geometric parameters of the cross-section
}

\author{
Dmitry Korolkov, ${ }^{1, *}$ and Marina Gravit ${ }^{2}$, and Maxim Aleksandrovskiy ${ }^{3}$ \\ ${ }^{1}$ Saint Petersburg State University of Architecture and Civil Engineering, 4 2nd Krasnoarmeyskaya \\ St.., 190005, Russian Federation \\ ${ }^{2}$ Peter the Great St.Petersburg Polytechnic University, 29 Politechnicheskaya St., St. Petersburg, \\ 195251, Russian Federation \\ ${ }^{3}$ Moscow State University of Civil Engineering, 26, Yaroslavskoye shosse, Moscow, 129337, Russia
}

\begin{abstract}
In this article, the authors propose a method for assessing the residual resource by changing the geometric parameters of wooden structures. A general formula for estimating the maximum service life is presented. Then a number of special cases are considered when calculating the ultimate service life for the first group of limiting states. As a result, formulas were derived for calculating the ultimate service life for various design cases: centrally tensioned, centrally compressed, bending members, members subject to an axial force with bending. The author considered the determination of the rate of change in geometric parameters at the macrolevel (visually observed changes) and microscopic (microcracks, breaks of bonds between atoms). Formulas for determining the rate of change of geometric parameters at the macro and micro levels are proposed. The advantages and disadvantages of this method are presented. The scope of its application is indicated.
\end{abstract}

\section{Introduction}

During the operation of wooden structures, the dimensions of the cross-section of structural elements change. In the limit, the value of these dimensions will be minimal. Such a change in time in the dimensions of the cross-section of the elements occurs at a certain speed. From this it follows that other geometric characteristics of the section also change. This fact can be used to determine the residual life of timber elements. To do this, subtract the actual service life from the maximum permissible service life. The maximum service life will be determined by the formula:

$$
T_{u l t}=\frac{P_{a c t}-P_{\min }}{v}
$$

$P_{a c t}-$ value of the parameter at the moment of monitoring the technical condition;

$P_{\text {min }}-$ minimum value of the parameter;

\footnotetext{
*Corresponding author: korol9520@yandex.ru
} 
$v$ - rate of change of the parameter value over time.

The rate of change of the cross-sectional parameters is calculated by the formula:

$$
v=\frac{P_{2}-P_{1}}{t_{2}-t_{1}}
$$

$P_{1}$ - parameter value at the time of control $\mathrm{t}_{1}$;

$P_{2}$ - parameter value at the time of control $\mathrm{t}_{2}$;

$t_{1}$ - time of the previous control;

$t_{2}$ - time instant of current control.

Since the rate of change of the cross-sectional parameters is not the same in time, it is more correct to write the formula in the following form:

$$
v=\frac{f\left(t_{2}\right)-f\left(t_{1}\right)}{t_{2}-t_{1}}
$$

$f\left(t_{2}\right)$ and $f\left(t_{1}\right)$ - are the values of the parameter function at times $t_{2}$ and $t_{1}$.

Later in this article, in the formulas for determining the maximum service life, the rate of change of the cross-sectional parameters will be written in the form of the symbol v, since the law itself can be represented by various dependencies and its choice depends on the specific case.

Formula (1) is a general case, and it can take on a different form depending on which cross-sectional parameter we have adopted.

In this article, in the future, we will consider various cases of determining the maximum service life only for elements of an integral section and without curvature.

Cases will be considered when calculating only the first group of limiting states.

\section{Materials and methods}

Design resistance of pine, spruce and European larch wood sorted by grades should be determined by the formula:

$$
R^{p}=R^{A} \cdot m_{\text {long }} \cdot \prod m_{i}
$$

$R^{A}-$ design resistance of wood, $\mathrm{MPa}$;

$m_{\text {long }}-$ coefficient of long-term strength corresponding to the load duration mode (table 1);

When determining the design resistance, the operating conditions factors should be applied where appropriate. Accepted in accordance with clause 6.9 according to state Standard of Russia SP 64.13330.2017 Wooden structures. Updated edition of SNiP II-2580 .

$m_{v}-$ coefficient taking into account different operating conditions;

$m_{t}$ - operating temperature factor;

$m_{b}$ - coefficient for bending, eccentrically compressed, compressed-bending and compressed glued elements of rectangular cross-section with a height of more than $50 \mathrm{~cm}$ values of the design resistance to bending and compression along the fibers;

$m_{0}=0.8-$ coefficient for tensile members with weakening in the design section and bending members from round timber with undercut in the design section;

$m_{a}=0.9-$ coefficient for elements deeply impregnated with flame retardants under pressure;

$m_{\text {layer }}-$ coefficient for bending, eccentrically compressed, compressed-bending and compressed glued wooden elements, depending on the thickness of the layers, the value of the design resistance to bending, shearing and compression along the fibers; 
$m_{\text {bent }}-$ coefficient for bent structural members values of design resistance to tension, compression and bending;

$m_{\text {ser.life }}-$ coefficient taken depending on the service life;

$m_{\text {crus. }}=1.15-$ coefficient for crushing across the fibers under loading conditions D-I (table 1);

Table 1. The value of the coefficients of long-term strength for various modes of loading.

\begin{tabular}{|c|c|c|c|}
\hline $\begin{array}{l}\text { Loading modes } \\
\text { designation }\end{array}$ & Characteristic of loading modes & $\begin{array}{l}\text { Reduced } \\
\text { estimated time of } \\
\text { the load, } s\end{array}$ & $\begin{array}{l}\text { Long-term } \\
\text { strength } \\
\text { coefficient } \mathrm{m}_{\text {long }}\end{array}$ \\
\hline A & $\begin{array}{l}\text { Linearly increasing load in standard } \\
\text { machine tests }\end{array}$ & $1-10$ & 1.0 \\
\hline B & $\begin{array}{l}\text { Combined action of constant and long- } \\
\text { term temporary loads, the stress from } \\
\text { which exceeds } 80 \% \text { of the total stress in } \\
\text { structural elements from all loads }\end{array}$ & $10^{8}-10^{9}$ & 0.53 \\
\hline $\mathrm{C}$ & $\begin{array}{l}\text { Combined action of constant and short- } \\
\text { term snow loads }\end{array}$ & $10^{6}-10^{7}$ & 0.66 \\
\hline D & $\begin{array}{l}\text { Combined action of constant and short- } \\
\text { term wind and (or) installation loads }\end{array}$ & $10^{3}-10^{4}$ & 0.8 \\
\hline $\mathrm{E}$ & $\begin{array}{l}\text { Combined action of constant and seismic } \\
\text { loads }\end{array}$ & $10-100$ & 0.92 \\
\hline $\mathrm{F}$ & Impulse and shock loads action & $10^{-1}-10^{-8}$ & $1.1-1.35$ \\
\hline G & $\begin{array}{l}\text { Combined action of constant and short- } \\
\text { term snow loads in fire conditions }\end{array}$ & $10^{3}-10^{4}$ & 0.8 \\
\hline $\mathrm{H}$ & $\begin{array}{l}\text { For supports of overhead power lines - } \\
\text { icy, assembly, wind with ice, from wire } \\
\text { strain at temperatures below average } \\
\text { annual }\end{array}$ & $10^{4}-10^{5}$ & 0.85 \\
\hline I & $\begin{array}{l}\text { For supports of overhead power lines - } \\
\text { in case of breakage of wires and cables }\end{array}$ & $10^{-1}-10^{--2}$ & 1.1 \\
\hline
\end{tabular}

\section{Results and discussion}

\subsection{Determination of the residual life of the centrally stretched elements}

The formula will look like this:

$$
T_{u l t}=\frac{F_{\text {net } a c t}-F_{\text {net } \min }}{v}
$$

$F_{\text {net act }}$ - actual net cross-sectional area of the element at the time of inspection;

$F_{\text {net min }}-$ he minimum net cross-sectional area of the element;

The minimum cross-sectional area is determined by the formula:

$$
F_{\min }=\frac{N}{R_{p}}
$$

$N$ - calculated longitudinal force;

$R_{p}-$ design tensile strength of wood along the grain.

After substitution in formula (5), we get:

$$
T_{\text {ult }}=\frac{F_{\text {net act }}-F_{\text {net } \min }}{v}=\frac{F_{\text {net } a c t}-\frac{N}{R_{p}}}{v}
$$




\subsection{Determination of the residual life of centrally compressed elements}

When calculating the strength, the formula will be similar to formula (5):

$$
T_{\text {ult }}=\frac{F_{\text {net act }}-F_{\text {net } \min }}{v}=\frac{F_{\text {net act }}-\frac{N}{R_{C}}}{v}
$$

$R_{c}$ - calculated resistance of wood to compression along the fibers.

When calculating the stability, the formula will take the form

$$
T_{u l t}=\frac{\varphi_{a c t} \cdot F_{c a l ~ a c t}-\varphi_{\min } \cdot F_{c a l m i n}}{v}=\frac{\varphi_{a c t} \cdot F_{c a l ~ a c t}-\frac{N}{R_{C}}}{v}
$$

$\varphi_{\text {act }}$ - buckling coefficient corresponding to the actual area at the time of the survey, which is determined:

with element flexibility $\lambda \leq 70$ :

$$
\varphi_{a c t}=1-a \cdot\left(\frac{\varphi_{a c t}}{100}\right)^{2}
$$

where coefficient $\mathrm{a}=0.8$ for wood and $\mathrm{a}=1.0$ for $\mathrm{LVL}$ and plywood.

with element flexibility $\lambda>70$ :

$$
\varphi_{\text {act }}=\frac{A}{\lambda_{\text {act }}^{2}}
$$

coefficient $\mathrm{A}=3000$ for wood and $\mathrm{A}=2500$ for plywood and wood from unidirectional veneer.

$\lambda_{\text {act }}-$ flexibility of the element with the actual area at the time of the survey, is determined by the formula:

$$
\lambda_{\text {act }}=\frac{l_{0}}{r_{\text {act }}}
$$

$l_{0}$ - calculated length of the element, determined by the formula:

$$
l_{0}=l \cdot \mu_{0}
$$

$l$ - free length of the element;

$\mu_{0}$ - coefficient determined according to clause 7.23 according to state Standard of Russia SP 64.13330.2017 Wooden structures. Updated edition of SNiP II-25-80.

$r_{\text {act }}$ - radius of gyration of the section of the element with the maximum gross dimensions relative to the $\mathrm{x}$ and $\mathrm{y}$ axes at the actual area.

$F_{\text {cal act }}$ - actual calculated cross-sectional area of the element;

Thus, formula (9) will take the form:

with element flexibility $\lambda \leq 70$ :

$$
T_{u l t}=\frac{\left(1-a \cdot\left(\frac{l \cdot \mu_{0}}{100 \cdot r_{a c t}}\right)^{2}\right) \cdot F_{c a l ~ a c t}-\frac{N}{R_{C}}}{v}
$$

with element flexibility $\lambda>70$ :

$$
T_{u l t}=\frac{\frac{A \cdot r_{a c t}^{2}}{\left(l \cdot \mu_{0}\right)^{2}} \cdot F_{c a l ~ a c t}-\frac{N}{R_{C}}}{v}
$$


When calculating the stability of centrally compressed elements of a height-variable section, formulas (14) and (15) take the form:

$$
\begin{aligned}
& T_{u l t}=\frac{\left(1-a \cdot\left(\frac{l \cdot \mu_{0}}{100 \cdot r_{a c t}}\right)^{2}\right) \cdot F_{c a l ~ a c t}-\frac{N}{R_{c} \cdot k_{g N}}}{v} \\
& T_{u l t}=\frac{\frac{A \cdot r_{c c t}^{2}}{\left(l \cdot \mu_{0}\right)^{2}} \cdot F_{c a l ~ a c t}-\frac{N}{R_{C} \cdot k_{g N}}}{v}
\end{aligned}
$$

$k_{\mathrm{g} N}-$ coefficient taking into account the variability of the section height, determined according to table D.2 of Appendix D (for elements of constant section $k_{\mathrm{gN}}=1$ ) according to state Standard of Russia SP 64.13330.2017 Wooden structures. Updated edition of SNiP II-25-80.

\subsection{Determination of the residual life of bending elements}

When calculating for normal stresses, the formula will be as follows:

$$
T_{u l t}=\frac{W_{a c t}-W_{\min }}{v}
$$

$W_{\text {act }}$ - actual calculated moment of resistance of the cross-section of the element at the time of inspection;

$W_{\text {min }}-$ minimum design moment of resistance of the element cross-section;

The minimum design moment of resistance is determined by the formula

$$
W_{\min }=\frac{M}{R_{i}}
$$

$R_{i}$ - design bending resistance;

$M$ - calculated bending moment.

After substitution in formula (18), we get:

$$
T_{u l t}=\frac{W_{a c t}-W_{\min }}{v}=\frac{W_{a c t}-\frac{M}{R_{i}}}{v}
$$

When calculating for shearing, the formula will look like:

$$
T_{u l t}=\frac{\left[\frac{s_{b r}^{\prime}}{I_{b r} \cdot b_{c a l}}\right]_{a c t}-\left[\frac{s_{b r}^{\prime}}{I_{b r} \cdot b_{c a l}}\right]_{\min }}{v}=\frac{\left[\frac{s_{b r}^{\prime}}{I_{b r} \cdot b_{c a l}}\right]_{a c t}-\frac{R_{s k}}{Q}}{v}
$$

$Q-$ design shear force;

$S_{b r}^{\prime}$ - gross static moment of the shear part of the element cross-section relative to the neutral axis;

$I_{b r}$ - gross moment of inertia of the element cross-section relative to the neutral axis;

$b_{c a l}-$ design width of the element section;

$R_{s k}-$ design shear resistance in bending.

When calculating for oblique bending:

$$
T_{u l t}=\frac{\left[\frac{M_{x}}{W_{x}}+\frac{M_{y}}{W_{y}}\right]_{a c t}-\left[\frac{M_{x}}{W_{x}}+\frac{M_{y}}{W_{y}}\right]_{\min }}{v}=\frac{\left[\frac{M_{x}}{W_{x}}+\frac{M_{y}}{W_{y}}\right]_{a c t}-R_{i}}{v}
$$


$M_{x}$ and $M_{y}-$ components of the design bending moment for the main axes of the section $\mathrm{x}$ and $\mathrm{y}$;

$W_{x}$ and $W_{y}$ - moments of resistance of the net cross-section relative to the main axes of the section $\mathrm{x}$ and $\mathrm{y}$.

When calculating the stability of a flat form of deformation of bending elements of a rectangular constant section:

$$
T_{u l t}=\frac{\varphi_{M a c t} \cdot W_{b r a c t}-\varphi_{M \min } \cdot W_{b r \min }}{v}=\frac{\varphi_{M a c t} \cdot W_{a c t}-\frac{M}{R_{i}}}{v}
$$

The coefficient $\varphi_{M}$ act for bending elements of a rectangular constant cross-section, hinged from displacement from the plane of bending and fixed from rotation around the longitudinal axis in the support sections, should be calculated by the formula:

$$
\varphi_{M \text { act }}=140 \frac{b_{a c t}^{2}}{l_{p} \cdot h_{a c t}} \cdot k_{f}
$$

$l_{p}$ - distance between the support sections of the element, and when fixing the compressed edge of the element at intermediate points from the displacement from the bending plane, the distance between these points;

$b_{\text {act }}$ - actual width of the cross-section;

$h_{\text {act }}$ - actual maximum cross-sectional height in the section $l_{p}$;

$k_{f}$ - coefficient depending on the shape of the diagram of bending moments in the section $l_{p}$, determined according to Table E.1 of Appendix E according to state Standard of Russia SP 64.13330.2017 Wooden structures. Updated edition of SNiP II-25-80.

After substitution, formula (23) will take the form:

$$
T_{u l t}=\frac{\left(140 \frac{b_{a c t}^{2}}{l_{p} \cdot h_{a c t}} \cdot k_{f}\right) \cdot W_{a c t}-\frac{M}{R_{i}}}{v}
$$

\subsection{Determination of the residual life of elements subject to axial bending force}

When calculating eccentrically stretched and stretched-bending members for normal stresses:

$$
T_{u l t}=\frac{\left[\frac{N}{F_{c a l}}+\frac{M_{D} \cdot R_{p}}{W_{c a l} R_{i}}\right]_{a c t}-\left[\frac{N}{F_{c a l}}+\frac{M_{D} \cdot R_{p}}{W_{c a l} R_{i}}\right]_{\min }}{v}=\frac{\left[\frac{N}{F_{c a l}}+\frac{M_{D} \cdot R_{p}}{W_{c a l} R_{i}}\right]_{a c t}-R_{i}}{v}
$$

$M_{D}$ - bending moment from the action of transverse and longitudinal loads, determined from the calculation according to the deformed scheme;

$F_{\text {cal }}-$ net calculated cross-sectional area.

When calculating the strength for normal stresses, eccentrically compressed and compressed-bending elements should be performed according to the formula:

$$
T_{u l t}=\frac{\left[\frac{N}{F_{c a l}}+\frac{M_{D}}{W_{c a l}}\right]_{a c t}-\left[\frac{N}{F_{c a l}}+\frac{M_{D}}{W_{c a l}}\right]_{\min }}{v}=\frac{\left[\frac{N}{F_{c a l}}+\frac{M_{D}}{W_{c a l}}\right]_{a c t}-R_{c}}{v}
$$

When calculating the shear strength of compressed-bending elements should be performed according to the formula (20), eccentrically compressed - according to the formula: 


$$
T_{u l t}=\frac{\left[\frac{Q \cdot S_{b r}^{\prime}}{I_{b r} \cdot b c a l}+\frac{0,75 \cdot N \cdot e}{b \cdot h^{2}}\right]_{a c t}-\left[\frac{Q \cdot S_{b r}^{\prime}}{I_{b r} \cdot b_{c a l}}+\frac{0,75 \cdot N \cdot e}{b \cdot h^{2}}\right]_{\min }}{v}=\frac{\left[\frac{Q \cdot S_{b r}^{\prime}}{I_{b r} \cdot b_{c a l}}+\frac{0.75 \cdot N \cdot e}{b \cdot h^{2}}\right]_{a c t}-R_{S k}}{v}
$$

$N$ - calculated longitudinal force;

$e-$ eccentricity of transfer of force $\mathrm{N}$.

When calculating the stability of a flat form of deformation of compressed-bending elements:

$$
T_{u l t}=\frac{\left[\frac{N}{\varphi \cdot R_{C} \cdot F_{b r}}+\left(\frac{M_{D}}{\varphi_{M} \cdot R_{i} \cdot W_{b r}}\right)^{n}\right]_{a c t}-1}{v}
$$

$n=2-$ for elements without fixing the stretched zone from the plane of deformation and $n=1$ for elements with such fixings.

After substitution of all terms according to item 7.20 (Standard of Russia SP 64.13330.2017 Wooden structures. Updated edition of SNiP II-25-80), formula (29) takes the form:

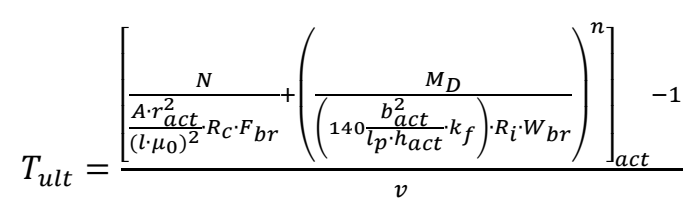

Since the calculation of the limiting service life of wooden elements is carried out at once according to several formulas, then the minimum of those obtained is taken as the final result.

\section{Conclusions}

Now let's talk about some aspects of calculating the maximum service life.

The first thing that should be addressed is the presence in a number of formulas of such a value as the calculated length of the element. When calculating the limiting service life, we proceed from the assumption that this value remains unchanged throughout the entire service life, i.e., firstly, the fastening scheme of the element does not change and, secondly, the change in the actual free length of the element is negligible. This means that the change in length occurs only due to the influence of the external environment.

It also follows that changing this value by changing the design scheme and (or) reducing the free length of the element will increase the maximum service life, which means that the residual resource will become larger.

The second thing you should pay attention to is that the calculation does not imply a change in geometric parameters as a result of artificial strengthening or weakening of the element cross-section. It turns out that by increasing the cross-section of the element, we thereby increased the maximum service life, and hence the value of the residual resource.

The third thing you should pay attention to is that the calculation assumes that the action of transverse and longitudinal forces, bending moments remains unchanged throughout the entire service life. At the same time, it is important to understand that the change in the magnitude of the efforts in most cases is associated not with a simple decrease in the load as such, but with a change in the structural scheme and strengthening of structures. Therefore, when considering the issue of increasing the residual resource by changing the value of efforts, it comes down to a comprehensive consideration of this issue. 
The advantage of this calculation method can be considered that we obtain objective values of the maximum service life and, accordingly, the residual resource, since the initial data are obtained during the instrumental examination.

The disadvantage of this approach can be considered its complexity or the impossibility of implementation in some cases in practice.

This method can be implemented directly when it is possible to directly measure the change in geometric parameters. For example, when wood decays, when you can clean the element from the decayed part.

Here the problem is divided into two.

The first problem is directly related to changes in geometric parameters. Access to structures is not always available.

The second problem is related to determining the rate of change of geometric parameters.

It can be divided directly into two levels: micro and macro.

Macrolevel is a directly observed change in geometric parameters.

Microlevel - changes occurring within an element and are not directly observable. These are microcracks and bond breaks between atoms.

When considering the rate of change of geometric parameters at the macro level, the question arises about the lack of data for the past period of operation. Since the rate of change in geometric parameters is not the same at different time intervals, in the absence of observation data, the estimate of the rate of change in geometric parameters will be incorrect and, accordingly, we will receive an incorrect value for the maximum service life.

To solve this problem, it is important to record the current values of geometric dimensions when organizing regular technical inspections. In this case, having a number of data, it is possible to apply regression analysis [1-19] and build equations for the dependence of changes in geometric parameters. The resulting equation must be substituted into formula (3). In some cases, it can be simplified.

Here are some examples. Let's derive formulas for speed if we know one-way regression equations. Let's build for linear regression and polynomial of the second order.

$$
\begin{aligned}
& v=\frac{\left(a \cdot t_{2}+m\right)-\left(a \cdot t_{1}+m\right)}{t_{2}-t_{1}}=\frac{a \cdot\left(t_{2}-t_{1}\right)}{t_{2}-t_{1}}=a \\
& v=\frac{\left(a \cdot t_{2}^{2}+b \cdot t_{2}+c\right)-\left(a \cdot t_{1}^{2}+b \cdot t_{1}+c\right)}{t_{2}-t_{1}}=a \cdot\left(t_{2}+t_{1}\right)+b
\end{aligned}
$$

For the micro level, everything is much more complicated.

We cannot directly observe the development of microcracks, therefore, to assess the rate of development of changes in geometric parameters, we can use equations of the Arrhenius type according to the thermofluctuation (kinetic) concept.

$$
v=v_{m} \cdot \exp \left[-\frac{U_{0}-\gamma \cdot \sigma}{R \cdot T}\left(1-\frac{T}{T_{m}}\right)\right]
$$

$R$ - gas constant;

$\gamma-$ structural and mechanical constant;

$U_{0}$ - maximum activation energy;

$v_{m}$ - limiting rate of parameter change;

$T$ - temperature;

$T_{m}$ - limiting temperature of existence of a solid;

$\sigma-$ stress. 
In conclusion, I would like to note that despite the fact that the proposed method was considered for wooden structures, it can be applied to other types of structures (reinforced concrete, metal, stone and composite).

\section{References}

1. C. Payan, O. Abraham, V. Garnier, Ultrasonic Methods. In Non-Destructive Testing and Evaluation of Civil Engineering Structures (Elsevier Inc., 2018) DOI: 10.1016/B978-1-78548-229-8.50002-9

2. Q.A. Vu, V. Garnier, J.F. Chaix, C. Payan, M. Lott, J.N. Eiras, Concrete cover characterisation using dynamic acousto-elastic testing and Rayleigh waves, Const. and Build. Mat. 114, 87-97 (2016) DOI: 10.1016/j.conbuildmat.2016.03.116

3. A.M.T. Hassan, S.W. Jones, Non-destructive testing of ultra high performance fibre reinforced concrete (UHPFRC): A feasibility study for using ultrasonic and resonant frequency testing techniques, Const. and Buil. Mat. 35, 361-367 (2012) DOI: 10.1016/j.conbuildmat.2012.04.047

4. V. Garnier, B. Piwakowski, O. Abraham, G. Villain, C. Payan, J.F. Chaix, Acoustic techniques for concrete evaluation: Improvements, comparisons and consistency, Const. and Build. Mat. 43, 598-613 (2013) DOI: 10.1016/j.conbuildmat.2013.01.035

5. T. Planès, E. Larose, A review of ultrasonic Coda Wave Interferometry in concrete, Cem. and Concr. Res. 53, 248-255 (2013) DOI: 10.1016/j.cemconres.2013.07.009

6. K. Schabowicz, Ultrasonic tomography - The latest nondestructive technique for testing concrete members - Description, test methodology, application example, Arch. of Civ. and Mech. Eng. 14, 295-303 (2014) DOI: 10.1016/j.acme.2013.10.006

7. F. Moradi-Marani, P. Rivard, C.P. Lamarche, S.A. Kodjo, Evaluating the damage in reinforced concrete slabs under bending test with the energy of ultrasonic waves, Const. and Build. Mat. 73, 663-673 (2014) DOI: 10.1016/j.conbuildmat.2014.09.050

8. Y. Xu, R. Jin, Measurement of reinforcement corrosion in concrete adopting ultrasonic tests and artificial neural network, Const. and Build. Mat. 177, 125-133 (2018) DOI: 10.1016/j.conbuildmat.2018.05.124

9. J. Wolf, S. Pirskawetz, A. Zang, Detection of crack propagation in concrete with embedded ultrasonic sensors, Eng. Frac. Mech. 146, 161-171 (2015) DOI: 10.1016/j.engfracmech.2015.07.058

10. H. Choi, J.S. Popovics, NDE application of ultrasonic tomography to a full-scale concrete structure, IEEE Transactions on Ultrasonics, Ferroelectrics, and Frequency Control 62, 1076-1085 (2015) DOI: 10.1109/TUFFC.2014.006962

11. O. Tsioulou, A. Lampropoulos, S. Paschalis, Combined Non-Destructive Testing (NDT) method for the evaluation of the mechanical characteristics of Ultra High Performance Fibre Reinforced Concrete (UHPFRC), Const. and Buil. Mat. 131, 66-77 (2017) DOI: 10.1016/j.conbuildmat.2016.11.068

12. G. Karaiskos, A. Deraemaeker, D.G. Aggelis, D. Van Hemelrijck, Monitoring of concrete structures using the ultrasonic pulse velocity method, Smart Mat. and Str. 24 (2015) DOI: 10.1088/0964-1726/24/11/113001

13. G. Karaiskos, E. Tsangouri, D.G. Aggelis, K. Van Tittelboom, N. De Belie, D. Van Hemelrijck, Performance monitoring of large-scale autonomously healed concrete beams under four-point bending through multiple non-destructive testing methods, Smart Mat. and Str. 25 (2016) DOI: 10.1088/0964-1726/25/5/055003 
14. M.V. Gravit, D. Serdjuks, A.V. Bardin, V. Prusakov, K. Buka-Vaivade, Fire Design Methods for Structures with Timber Framework, Mag. of Civ. Eng. 85(1), 92-106 (2019) DOI: 10.18720/MCE.85.8

15. K. Buka-Vaivade, D. Serdjuks, V. Goremikins, L. Pakrastins, N.I. Vatin, Suspension structure with cross-laminated timber deck panels, Mag. of Civ. Eng. 83(7), 126-135 (2018) DOI: 10.18720/MCE.83.12

16. R. Vasiljevs, D. Serdjuks, K. Buka-Vaivade, A. Podkoritovs, N. Vatin, Load-carrying capacity of timber-concrete composite panels, Mag. of Civ. Eng. 93(1), 60-70 (2020) DOI: 10.18720/MCE.93.6

17. V. Goremikins, D. Serdjuks, K. Buka-Vaivade, L. Pakrastins, N.I. Vatin, Prediction of behaviour of prestressed suspension bridge with timber deck panels, The Balt. Jour. of Road and Brid. Eng. 12(4), 234-240 (2017) DOI: 10.3846/bjrbe.2017.29

18. R. Vasiljevs, D. Serdjuks, J. Gerasimova, K. Buka-Vaivade, A. Orhun Erüz, Behaviour of timber-concrete joints in hybrid members subjected to flexure, IOP Confernce Series: Mat. Sc. and Eng. 660, 1-9, 012050 (2019) DOI: 10.1088 / 1757-899X / 660/1/012050

19. R. Vasiljevs, D. Serdjuks, K. Buka-Vaivade, A. Podkoritovs, N. Vatin, Load-carrying capacity of timber-concrete composite panels, Mag. of Civ. Eng. 93(1), 60-70 (2020) DOI: 10.18720/MCE.93.6 